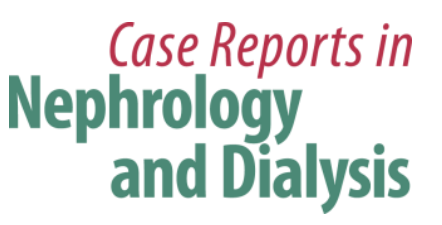

Case Rep Nephrol Dial 2016;6:40-45

DOI: $10.1159 / 000444875$

Publisnea onithe: IVIarch 18, 2016

\title{
Two Cases of Hypophosphatemia with Increased Renal Phosphate Excretion in Legionella Pneumonia
}

\author{
Shuhei Watanabe ${ }^{a, b}$ Keiji Kono ${ }^{a, b}$ Hideki Fujii ${ }^{a}$ Kentaro Nakai \\ Shunsuke Goto ${ }^{a}$ Shinichi Nishi ${ }^{a}$ \\ a Division of Nephrology and Kidney Center, Kobe University Graduate School of Medicine, \\ Kobe, and ${ }^{b}$ Division of Nephrology, Akashi Medical Center, Akashi, Japan
}

\section{Key Words}

Hypophosphatemia - Renal tubular dysfunction - Legionella pneumonia - Fibroblast growth factor- $23 \cdot 1,25(\mathrm{OH})_{2}$ vitamin D

\begin{abstract}
We encountered 2 cases of hypophosphatemia due to Legionella pneumonia. Both cases showed increased urinary phosphate excretion and renal tubular dysfunction, which ameliorated with recovery from Legionella pneumonia. Serum fibroblast growth factor-23 level was suppressed, whereas serum $1,25(\mathrm{OH})_{2}$ vitamin $D$ and parathyroid hormone levels were normal. Delayed elevation of serum $1,25(\mathrm{OH})_{2}$ vitamin D levels was observed with improvement in renal tubular function. These findings suggested hypophosphatemia might be mediated by renal tubular dysfunction.

(C) 2016 The Author(s)

Published by S. Karger AG, Basel
\end{abstract}

\section{Background}

Legionella pneumophila is a common cause of community-acquired pneumonia. It is well known that patients with Legionella pneumonia present with multisystemic extrapulmonary manifestations, such as electrolyte disorders, renal dysfunction, and liver dysfunction [1]. Among the electrolyte disorders, hypophosphatemia is noted as one of the common features and is used as part of the diagnostic criteria for Legionella pneumonia [2]. However, its detailed mechanism remains unclear. In general, phosphate homeostasis is mainly regulated by the endocrine system, specifically by parathyroid hormone $(\mathrm{PTH}), 1,25(\mathrm{OH})_{2}$ vitamin $\mathrm{D}$, and fibroblast growth factor-23 (FGF-23) [3]. We report 2 cases of Legionella pneumonia compli-

\section{KARGER}

Keiji Kono, MD, PhD

Division of Nephrology and Kidney Center, Kobe University Graduate School of Medicine, 7-5-2, Kusunoki-cho, Chuo-ku

Kobe, Hyogo 650-0017 (Japan)

E-Mailkkono@med.kobe-u.ac.jp 


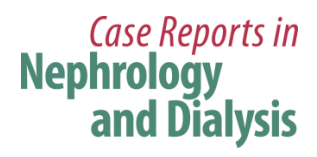

Case Rep Nephrol Dial 2016;6:40-45 \begin{tabular}{l|l}
\hline DOI: $10.1159 / 000444875$ & $\begin{array}{l}\text { C } 2016 \text { The Author(s). Published by S. Karger AG, Basel } \\
\text { www.karger.com/cnd }\end{array}$
\end{tabular}

Watanabe et al.: Two Cases of Hypophosphatemia with Increased Renal Phosphate Excretion in Legionella Pneumonia

cated with hypophosphatemia and the evaluated mineral homeostatic regulators associated with phosphate control.

\section{Case Presentations}

Case 1

A 54-year-old male visited the emergency department because of fatigue and fever a day before admission. He did not have any respiratory or abdominal symptoms. The patient's medical history revealed that he had started treatment for hypertension 3 years ago and that he had been prescribed valsartan $(80 \mathrm{mg} /$ day $)$ and amlodipine $(5 \mathrm{mg} /$ day). Physical examination showed a BMI of $27.5 \mathrm{~kg} / \mathrm{m}^{2}$, blood pressure of $156 / 96 \mathrm{~mm} \mathrm{Hg}$, pulse rate of 137 bpm, temperature of $40.1^{\circ} \mathrm{C}$, oxygen saturation of $95 \%$ (room air), and crackles at the base of the right lung.

CT was performed, and ground-glass opacities were detected in the right middle and lower lobes. Considering these clinical findings together with a positive urinary test for $L e$ gionella antigen (Binax, Portland, Maine, USA), a diagnosis of Legionella pneumonia was confirmed. Laboratory data on admission are summarized in table 1 . The patient had mild renal dysfunction and hypophosphatemia, while the other electrolytes were within the normal range. Glycemic control was within the ideal range. Arterial blood gas measurement demonstrated hypoxemia and mild respiratory alkalosis. Furthermore, urinary analysis revealed proteinuria, glycosuria, panaminoaciduria, and phosphaturia. Urinary $\mathrm{N}$-acetyl- $\beta$-Dglucosaminidase (U-NAG) and urinary $\beta 2$-microglobulin (U- $\beta 2-\mathrm{MG}$ ) levels were also elevated.

After initiation of antibiotic therapy, serum C-reactive protein (CRP) levels improved (fig. 1). The elevation of U-NAG and U- $\beta 2-\mathrm{MG}$ also improved with recovery from pneumonia. Glycosuria, proteinuria, panaminoaciduria, and phosphaturia also improved rapidly. Serum phosphate and ratio of maximal tubular reabsorption of phosphorus/glomerular filtration rate (TmP/GFR) levels reached the normal range on the 5th day after admission.

Case 2

A 71-year-old male presented with fever, nausea, and fatigue 3 days before admission. He did not have any respiratory or abdominal symptoms. He had been previously healthy and had not taken any drugs. Physical examination showed a BMI of $21.7 \mathrm{~kg} / \mathrm{m}^{2}$, blood pressure of $140 / 90 \mathrm{~mm} \mathrm{Hg}$, pulse rate of $102 \mathrm{bpm}$, temperature of $40.1^{\circ} \mathrm{C}$, oxygen saturation of 95\% (2 liter/min, nasal cannula), and crackles in the left lung.

Chest CT showed ground-glass opacities in all lobes of the left lung. A urinary test for Legionella antigen was positive, and the diagnosis of Legionella pneumonia was confirmed. Laboratory analyses on admission are summarized in table 1 . Serum creatinine levels were within the normal range $(0.88 \mathrm{mg} / \mathrm{dl})$, and estimated GFR was $65.6 \mathrm{ml} / \mathrm{min} / 1.73 \mathrm{~m}^{2}$. Arterial blood gas measurement revealed hypoxemia and mild respiratory alkalosis. Hypophosphatemia, phosphaturia, and renal tubular dysfunction were also present. As for mineral homeostatic regulators, serum FGF-23 level was unmeasurably low, 1,25(OH) $)_{2}$ vitamin D was within the normal range $(57.2 \mathrm{pg} / \mathrm{ml}$, normal range: $20.0-60.0)$, and intact PTH (i-PTH) was not elevated $(30 \mathrm{pg} / \mathrm{ml}$, normal range: $15.0-68.0)$ on admission.

After administration of ciprofloxacin at $600 \mathrm{mg} /$ day, the levels of serum CRP, U-NAG, and U- $32-\mathrm{MG}$ improved (fig. 2 ). Renal tubular dysfunction, including glycosuria, proteinuria, panaminoaciduria, and phosphaturia, improved with recovery from pneumonia. Delayed elevation of $1,25(\mathrm{OH})_{2}$ vitamin D levels was present on the 3rd day after admission. Serum 


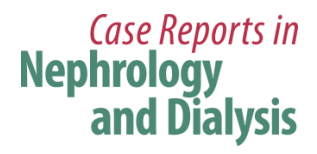

\begin{tabular}{l|l}
\hline Case Rep Nephrol Dial 2016;6:40-45 \\
\hline DOI: $10.1159 / 000444875$ & $\begin{array}{l}\text { (c) 2016 The Author(s). Published by S. Karger AG, Basel } \\
\text { www.karger.com/cnd }\end{array}$ \\
\hline
\end{tabular}

Watanabe et al.: Two Cases of Hypophosphatemia with Increased Renal Phosphate Excretion in Legionella Pneumonia

FGF-23 levels gradually increased with improvement in renal tubular dysfunction, serum phosphate, and TmP/GFR levels. Serum i-PTH levels did not increase during the whole period.

\section{Discussion}

Hypophosphatemia is a common complication associated with Legionella pneumonia, although the underlying mechanism is unclear [1]. We presented 2 cases of Legionella pneumonia with hypophosphatemia. Both showed increased renal phosphate excretion on admission, which rapidly resolved during recovery from Legionella pneumonia.

Renal phosphate reabsorption takes place mostly in the proximal renal tubules. In general, the etiology of increased renal phosphate excretion includes 2 main causes: proximal renal tubular dysfunction, such as Fanconi syndrome, and a disorder of the physiological mineral homeostatic regulators such as FGF-23, PTH, and 1,25(OH) $)_{2}$ vitamin D [4]. The present cases demonstrated elevated U-NAG and U- $\beta_{2}$-MG levels, proteinuria, glycosuria, and panaminoaciduria, all of which resolved rapidly with improvement of Legionella pneumonia. These findings suggest that proximal renal tubular dysfunction may occur transiently in cases of Legionella pneumonia. A recent report also demonstrated that Legionella pneumonia triggered the acquired Fanconi syndrome [5]. However, no report has measured mineral homeostatic regulators in Legionella pneumonia. In the present case 2, serum FGF-23 level was unmeasurably low on admission and gradually increased as serum phosphate levels normalized, whereas serum PTH levels were not elevated during the whole period. These results suggest that both FGF-23 and PTH were not responsible for hypophosphatemia in Legionella pneumonia. Serum $1,25(\mathrm{OH})_{2}$ vitamin D level was within the normal range on admission despite the presence of severe hypophosphatemia. Three days after admission, delayed elevation of serum $1,25(\mathrm{OH})_{2}$ vitamin $\mathrm{D}$ level was observed with improvement of renal tubular dysfunction. Hypophosphatemia has been postulated to accelerate the production of $1,25(\mathrm{OH})_{2}$ vitamin D through the activation of cytochrome p450 27B1 (CYP27B1) in renal proximal tubules $[6,7]$. Previous reports have mentioned that impaired activation of $1,25(\mathrm{OH})_{2}$ vitamin $\mathrm{D}$ is induced by proximal renal tubular dysfunction associated with tubulointerstitial nephritis or Fanconi syndrome [8, 9]. Taking these facts into consideration, we speculated that there was a possibility that proximal renal tubular dysfunction caused the delayed elevation of $1,25(\mathrm{OH})_{2}$ vitamin $\mathrm{D}$. It could be one of the additive reasons for hypophosphatemia in Legionella pneumonia. Interestingly, serum FGF-23 levels gradually increased with improvement in renal tubular function, serum phosphate, and TmP/GFR levels. Although the regulator of FGF-23 is still not fully understood, the time course of serum FGF23 levels gives us speculation that renal tubular function, renal phosphate excretion, and serum phosphate levels might contribute to the regulation of FGF-23 secretion.

Known causes of proximal renal tubular dysfunction include congenital diseases, adverse drug reactions, M-protein disorders, collagen diseases, and exposure to heavy metals [10]. In the present cases, proximal renal tubular dysfunction could have been caused by Legionella pneumonia itself because the findings of renal tubular dysfunction were resolved when Legionella pneumonia improved, and the patients did not have any other causes. However, its mechanism remains unclear. Legionella pneumophila is a well-known facultative intracellular bacterium. To avoid interaction with host cell lysosomes and proliferative pathogens, Legionella pneumophila requires components of many host cell organelles, such as endosomes, mitochondria, ribosomes, and endoplasmic reticulum [11]. As for renal complications, tubulointerstitial nephritis and the presence of Legionella pneumophila itself were 
Watanabe et al.: Two Cases of Hypophosphatemia with Increased Renal Phosphate Excretion in Legionella Pneumonia

confirmed by renal biopsy [12-14]. Histologically, renal proximal tubules include numerous mitochondria required to supply energy for reabsorption [15]. Considering these features, we speculated that renal proximal tubules might be the most susceptible tissues because of the presence of mitochondria-rich lesions.

As a limitation, we evaluated mineral homeostatic regulators in only 1 of the present cases. However, there were no previous reports that showed its regulators in Legionella pneumonia, and thereby we considered that the present cases were worth reporting.

In conclusion, our cases suggested that hypophosphatemia due to Legionella pneumonia was caused not by FGF-23 and PTH but by renal tubular dysfunction. Furthermore, delayed $1,25(\mathrm{OH})_{2}$ vitamin D activation may initially affect hypophosphatemia.

\section{Acknowledgements}

This work was partially supported by funds for kidney disease research from the Hyogo Prefecture Health Promotion Association.

\section{Statement of Ethics}

The authors have no ethical conflicts to disclose.

\section{Disclosure Statement}

The authors have no conflicts of interest to disclose.

\section{References}

1 Cunha BA: Legionnaires' disease: clinical differentiation from typical and other atypical pneumonias. Infect Dis Clin North Am 2010;24:73-105.

-2 Gupta SK, Imperiale TF, Sarosi GA: Evaluation of the Winthrop-University Hospital criteria to identify Legionella pneumonia. Chest 2001;120:1064-1071.

-3 Lederer E: Regulation of serum phosphate. J Physiol 2014;592:3985-3995.

4 Gaasbeek A, Meinders AE: Hypophosphatemia: an update on its etiology and treatment. Am J Med 2005;118:1094-1101.

-5 Kinoshita-Katahashi N, Fukasawa H, Ishigaki S, Isobe S, Imokawa S, Fujigaki Y, Furuya R: Acquired Fanconi syndrome in patients with Legionella pneumonia. BMC Nephrol 2013;14:171.

6 Maierhofer WJ, Gray RW, Lemann J Jr: Phosphate deprivation increases serum1,25-(OH $)_{2}$-vitamin D concentrations in healthy men. Kidney Int 1984;25:571-575.

7 Shinki T, Shimada H, Wakino S, Anazawa H, Hayashi M, Saruta T, DeLuca HF, Suda T: Cloning and expression of rat 25-hydroxyvitamin D3-1alpha-hydroxylase cDNA. Proc Natl Acad Sci USA 1997; 94:12920-12925.

8 Saha H, Mustonen J, Pietilä K, Pasternack A: Metabolism of calcium and vitamin D3 in patients with acute tubulointerstitial nephritis: a study of 41 patients with nephropathia epidemica. Nephron 1993;63:159163.

-9 Colussi G, De Ferrari ME, Surian M, Malberti F, Rombolà G, Pontoriero G, Galvanini G, Minetti L: Vitamin D metabolites and osteomalacia in the human Fanconi syndrome. Proc Eur Dial Transplant Assoc Eur Ren Assoc 1985;21:756-760.

10 Haque SK, Ariceta G, Batlle D: Proximal renal tubular acidosis: a not so rare disorder of multiple etiologies. Nephrol Dial Transplant 2014;27:4273-4287.

11 Newton HJ, Ang DK, van Driel IR, Hartland EL: Molecular pathogenesis of infections caused by Legionella pneumophila. Clin Microbiol Rev 2010;23:274-298. 
Case Reports in

Nephrology

and Dialysis

\begin{tabular}{l|l}
\hline Case Rep Nephrol Dial 2016;6:40-45 \\
\hline DOI: 10.1159/000444875 & $\begin{array}{l}\text { C } 2016 \text { The Author(s). Published by S. Karger AG, Basel } \\
\text { www.karger.com/cnd }\end{array}$ \\
\hline
\end{tabular}

Watanabe et al.: Two Cases of Hypophosphatemia with Increased Renal Phosphate Excretion in Legionella Pneumonia

12 Daumas A, El-Mekaoui F, Bataille S, Daniel L, Caporossi JM, Fournier PE, Burtey S, Dussol B, Berland Y, Jourde-Chiche N: Acute tubulointerstitial nephritis complicating Legionnaires' disease: a case report. J Med Case Rep 2012;6:100.

$>13$ Evans CP, Winn WC Jr: Extrathoracic localization of Legionella pneumophilia in Legionnaires' pneumonia. Am J Clin Pathol 1981;76:813-815.

14 Shah A, Check F, Baskin S, Reyman T, Menard R: Legionnaires' disease and acute renal failure: case report and review. Clin Infect Dis 1992;14:204-247.

-15 Zhuo JL, Li XC: Proximal nephron. Compr Physiol 2013;3:1079-1123.

Table 1. Laboratory findings on admission

\begin{tabular}{|c|c|c|c|}
\hline & Reference & Patient 1 & Patient 2 \\
\hline \multicolumn{4}{|l|}{ Biochemistry (serum) } \\
\hline Creatinine, mg/dl & $0.5-1.2$ & 1.39 & 0.88 \\
\hline $\mathrm{eGFR}, \mathrm{ml} / \mathrm{min} / 1.73 \mathrm{~m}^{2}$ & & 43.1 & 65.6 \\
\hline Urea nitrogen, mg/dl & $8.0-20.0$ & 20.2 & 18.4 \\
\hline Sodium, $\mathrm{mEq} / \mathrm{l}$ & $135-147$ & 137 & 132 \\
\hline Potassium, mEq/l & $3.3-4.8$ & 3.6 & 4.1 \\
\hline Chloride, $\mathrm{mEq} / \mathrm{l}$ & 98-108 & 101 & 102 \\
\hline Phosphate, mg/dl & $2.7-4.7$ & 1.2 & 1.8 \\
\hline Corrected calcium, mg/dl & 8.6-11.0 & 8.7 & 9.3 \\
\hline Magnesium, mg/dl & $1.7-2.4$ & 1.8 & 2.1 \\
\hline $\mathrm{CRP}, \mathrm{mg} / \mathrm{dl}$ & $0-0.3$ & 25.3 & 30.9 \\
\hline Glucose, mg/dl & $70-109$ & 141 & 176 \\
\hline \multicolumn{4}{|l|}{ Blood gasses } \\
\hline $\mathrm{pH}$ & $7.35-7.45$ & 7.485 & 7.458 \\
\hline $\mathrm{pCO}_{2}, \mathrm{~mm} \mathrm{Hg}$ & $35-45$ & 30.9 & 27.7 \\
\hline $\mathrm{HCO}_{3}^{-}, \mathrm{mmol} / \mathrm{l}$ & $23-28$ & 22.8 & 19.1 \\
\hline \multicolumn{4}{|l|}{ Urinalysis } \\
\hline $\mathrm{pH}$ & $4.8-7.5$ & 6.5 & 6.0 \\
\hline Proteinuria & & $4+$ & $2+$ \\
\hline Proteinuria, g/gCr & & 0.4 & 1.1 \\
\hline Glucose & & $2+$ & $2+$ \\
\hline Glucose, mg/dl & $0-30$ & 469 & 926 \\
\hline NAG, IU/l & $0-7.4$ & 11.3 & 16.6 \\
\hline$\beta 2-\mathrm{MG}, \mu \mathrm{g} / \mathrm{l}$ & $20-300$ & 54,400 & 80,800 \\
\hline TRP, $\%$ & & 87 & 74 \\
\hline $\mathrm{TmP} / \mathrm{GFR}$ & & 1.8 & 1.32 \\
\hline Panaminoaciduria & & + & + \\
\hline \multicolumn{4}{|l|}{ Mineral homeostatic regulators } \\
\hline $1,25(\mathrm{OH})_{2}$ vitamin $\mathrm{D}, \mathrm{pg} / \mathrm{ml}$ & $20.0-60.0$ & & 57.2 \\
\hline i-PTH, pg/ml & $15.0-68.0$ & & 30 \\
\hline FGF-23, pg/ml & & & $<5$ \\
\hline
\end{tabular}

eGFR = Estimated GFR; TRP = tubular reabsorption of phosphate. 
Case Reports in

Nephrology

and Dialysis
Case Rep Nephrol Dial 2016;6:40-45

\begin{tabular}{l|l}
\hline DOI: $10.1159 / 000444875$ & C 2016 The Author(s). Published by S. Karger AG, Basel
\end{tabular} www.karger.com/cnd

Watanabe et al.: Two Cases of Hypophosphatemia with Increased Renal Phosphate Excretion in Legionella Pneumonia
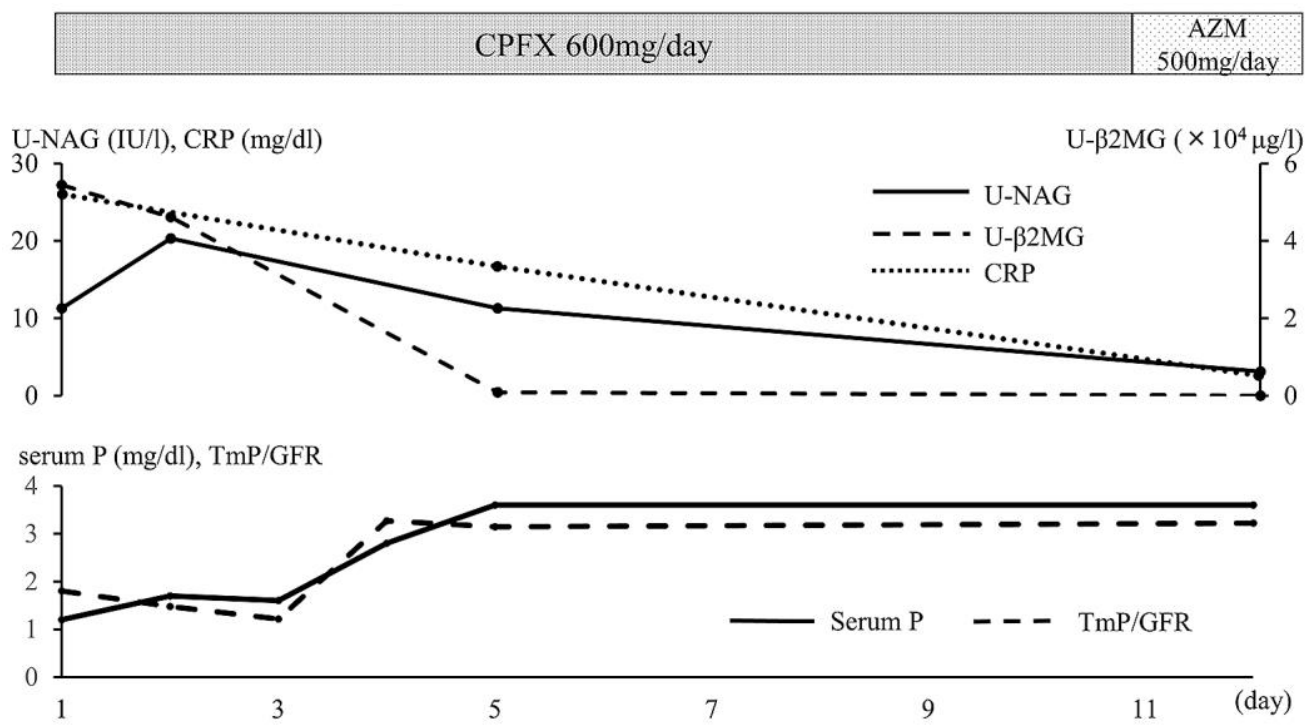

Fig. 1. Clinical course of case $1 . \mathrm{CPFX}=$ Ciprofloxacin; $\mathrm{AZM}=$ azithromycin; $\mathrm{P}=$ phosphate.
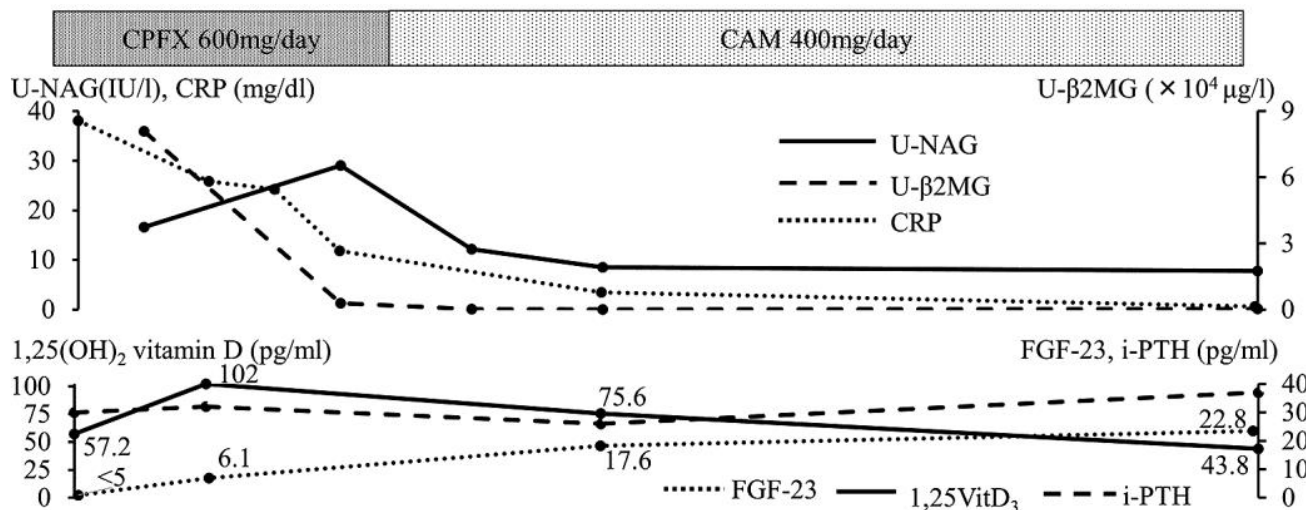

serum $\mathrm{P}(\mathrm{mg} / \mathrm{dl}), \mathrm{TmP} / \mathrm{GFR}$

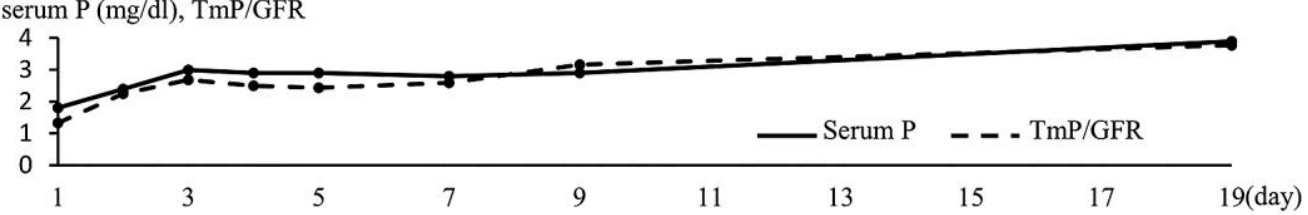

Fig. 2. Clinical course of case 2 . $C P F X=$ Ciprofloxacin; $C A M=$ clarithromycin; $P=$ phosphate. 